\title{
Evaluation of morpho-physiological traits under drought stress conditions in barley (Hordeum vulgare L.)
}

\author{
T. ISTANBULI*,+, M. BAUM ${ }^{* *}$, H. TOUCHAN***, and A. HAMWIEH* \\ International Center for Agricultural Research in the Dry Areas (ICARDA), Beirut, Lebanon* \\ International Center for Agricultural Research in the Dry Areas (ICARDA), Rabat, Morocco** \\ Department of Field Crops, Faculty of Agriculture, University of Aleppo, Syria ${ }^{* * *}$
}

\begin{abstract}
Drought stress is one of the major constraints limiting the production and productivity of barley. We tried to identify some indicators related to plant productivity by analyzing some agro-morphological and physiological traits in recombinant inbred lines (RILs). Plants were exposed to three water treatments: well-watered at 70\% available water content (AWC), mild drought stress at 35\% AWC, and severe drought stress at 10\% AWC. Our results revealed that drought significantly affected most of the studied morpho-physiological traits resulting in strong decreases in yield and the studied traits. We did not observe a significant difference in water-use efficiency between severe and mild drought conditions. Therefore, the mild stress treatment was considered as the most suitable water level in our study. Genotypes with the most tillers and spikes, the highest 1,000-grain mass, and biological yields achieved higher grain yields under all water stress conditions. Therefore, these traits could be considered as useful tools in breeding programs.
\end{abstract}

Additional key words: chlorophyll fluorescence; photosynthesis; stomatal conductance; water stress treatment; yield component.

\section{Introduction}

Barley (Hordeum vulgare L.) is a major cereal crop. It is well adapted to various abiotic stresses in the dry areas of West Asia and North Africa (Grando et al. 2005, Baum et al. 2007). Barley is cultivated on more than 40 million hectares in developing countries. In most developing countries, where it is subjected to extreme water deficits during dry seasons, it is often the only rain-fed crop that farmers can grow (Ceccarelli 1994). As a result, barley has been selected or bred for specific adaptations to abiotic stresses in geographically distinct areas of the world. This adaptation of genetically diverse germplasm to similar environmental conditions over a wide geographical range can be exploited for breeding and germplasm exchange. For example, barley germplasm bred by the International Center for Agricultural Research in the Dry Areas, Syria (ICARDA) for the marginal environments of West Asia and Northern Africa (WANA) showed good adaptation to dry southern Australian environments and vice versa (Rollins et al. 2013b).

Drought affects plant morphological and physiological traits, and causes metabolic modifications, which may lead to a decreased grain yield (Ludlow and Muchow 1990). Yield losses due to drought are estimated to vary from 17 to $70 \%$ (Ahmadizadeh et al. 2011). Stress adaptation in barley has been attributed to genetic variation in morphological traits (von Korff et al. 2008, Rollins et al. 2013a) and morpho-physiological traits (Rollins et al. 2013b).

Many morphological and physiological characteristics are affected by drought stress (Ahmadizadeh et al. 2011, Lonbani and Arzani 2011, Rollins et al. 2013b). Selection efficiency could be improved if a particular physiological and/or morphological trait related to improved seed yield under drought is identified and used in the selection process (Ludlow and Muchow 1990, Jatoi et al. 2011). Li et al. (2006), Kalaji and Guo (2008), and Kalaji et al. (2011a,b; 2012) reported that chlorophyll content (Chl) and some chlorophyll fluorescence $(\mathrm{ChF})$ parameters could be considered as reliable indicators for drought tolerance in barley germplasm. Chl fluorescence has been used as a rapid technique to estimate the quantum efficiency of photosynthetic apparatus, and PSII performance (Roohi

Received 20 January 2019, accepted 13 May 2020.

${ }^{+}$Corresponding author; e-mail: t.istanbuli@,cgiar.org

Abbreviations: ARKE - Arta Keel population; AWC - available water content; BY - biological yield; ChF - chlorophyll fluorescence measurements; DM - dry mass; $E$ - transpiration; $F M$ - fresh mass; $\mathrm{F}_{\mathrm{v}} / \mathrm{F}_{\mathrm{m}}$ - maximum photochemical efficiency; $\mathrm{GM}$ - 1,000-grain mass; $g_{\mathrm{s}}$ - stomatal conductance; GY - grain yield; HI - harvest index; MS - mild stress treatment; OA - osmotic adjustment; $\mathrm{OP}$ - osmotic potential; PH - plant height; $P_{\mathrm{N}}$ - net photosynthetic rate; QTL - quantitative trait locus; RILs - recombinant inbred lines; RT - relative turgidity; SL - spike length; SN - number of spikes per plant; SS - severe stress treatment; Ti - number of tillers; TM turgid mass; WUE - water-use efficiency; WW - well-watered treatment.

Acknowledgments: This work was supported by the strategic program funding of the Biodiversity and Crop Improvement (BCI) at the International Center for Agricultural Research in the Dry Areas (ICARDA). Authors are grateful to the Arab Fund for Economic and Social Development (AFESD) and the CGIAR Research Program on Grain Legumes and Dryland cereals for their partial financial support to this research. 
et al. 2013, Kalaji et al. 2014, 2017). Several studies reported that a water deficit leads to a significant inhibition of photosynthesis (Li et al. 2006, Roohi et al. 2013, Chéour et al. 2014, Dunic et al. 2015). Stomatal closure is one of the earliest plant responses to drought stress limiting the $\mathrm{CO}_{2}$ diffusion to chloroplast, and reducing photosynthetic activity substantially (Pinheiro and Chaves 2011). Chéour et al. (2014) reported that barley plants subjected to water stress showed lower relative water and Chl contents and higher contents of proline. Rollins et al. (2013b) indicated that leaf proteins were differentially regulated in response to drought, heat, and combined stresses in the context of the morphological and physiological changes for two genotypes: Arta (Syrian landrace) and Keel (Australian cultivar). These genotypes, the parents of the RIL population used in this study, demonstrated significant reductions in biomass and yield under drought, reduction in photosynthetic performance and protein under heat and combinations of heat and drought. In another study for the same RIL population ARKE, which identified QTL-influencing agronomic performance in rain-fed Mediterranean environments at two locations in Syria for four years with two sowing dates (autumn and winter), obtained results showing the genotypic variability in annual yields, presumably caused by interannual differences in rainfall distribution (Rollins et al. 2013a).

Plants relative turgidity (RT), relative water content (RWC) as well as osmotic potential (OP) are commonly used indicators to assess plant water status. The former is a measure of plant water status resulting from a cellular water deficit, while osmotic adjustment (OA) is probably the most important mechanism for maintaining physiological activity (Ludlow and Muchow 1990). It is an appropriate estimate of plant water status as affected by leaf water potential and OA (Baum et al. 2007). Many studies have examined the relationship between OA and grain yield under water stress conditions and the results show a positive relationship between OA and grain yield in wheat (Moinuddin et al. 2005) and barley (González et al. 2008, Behbahanizadeh et al. 2014).

Some morphological and agronomic traits, which are correlated to yield under drought, may be used in breeding programs to improve yield under drought stress conditions (Lonbani and Arzani 2011). Drought stress treatments reduced the grain yield, the number of tillers, spikes, and grains per plant (Samarah 2005). A strong positive correlation has been observed between the Chl content, some Chl fluorescence parameters, and yield under water stress in barley under drought conditions (Li et al. 2006). As previously mentioned, several studies have indicated the effect of drought stress on barley in response to morphophysiological parameters. However, since physiological parameters are more sensitive than morphological parameters in distinguishing drought stress treatments, it is necessary to know which of these parameters is more responsive to drought stress conditions. Therefore, the objective of this experiment was to identify indicators related to productivity (drought tolerance) through an analysis of morpho-physiological and yield traits in barley (Hordeum vulgare L.).

\section{Materials and methods}

Plant material and growth conditions: The present study was conducted during seasons 2008-2009 at ICARDA, Tel Hadya, Aleppo, Syria, in a greenhouse (16/8-h day/night at $27 / 18^{\circ} \mathrm{C}$ day/night) using a randomized complete block design (RCBD), with four replications. A total of 50 seeds from each of the RILs were planted in a plastic tray, filled by mixture of soil and peat moss in a volume ratio of $3: 1$. After germination, 36 seedlings from each of the RILs and 4-week-old parents were vernalized and transferred into a $2.5-\mathrm{kg}$ pot capacity with three plants in each pot $(15 \mathrm{~cm}$ in height and $16 \mathrm{~cm}$ in diameter), filled with $2 \mathrm{~kg}$ of sterilized soil and containing approximately $6 \%$ of water. The soil field capacity, wilting point, and AWC were measured at ICARDA soil laboratory according to a protocol described by Ryan et al. (2001). Out of $499 \mathrm{~F}_{7}$ RILs derived from a cross between the Syrian susceptible line 'Arta' and the Australian tolerant line 'Keel', only the first 40 RILs were used for this study. Arta is a two-row pure highyielding line selected from the Syrian white-seed landrace 'Arabi Abiad'. It is well adapted to Syrian conditions and combines a high number of tillers and high kernel mass, but is susceptible to lodging under high-yielding conditions. Keel is a two-row spring feed barley variety, which was developed by the South Australian Barley Improvement Program. It is a high-yielding line, which is adapted to severe drought stress and is resistant to lodging, early flowering, and plant height. Both parents are well adapted to low rainfall conditions $(250-375 \mathrm{~mm})$ with a high yield stability. The main objective of this cross was to develop lines combining the tillering ability of the Arta line with the plant height and severe drought adaptation of the Keel line (Grando et al. 2001, Rollins et al. 2013a). At the grain-filling stage, plants were subjected to three drought stress levels: 10,35 , and $70 \%$ of the soil AWC representing severe stress (SS), mild stress (MS), and well-watered (WW) conditions, respectively.

Pots were weighed daily and maintained at the desired soil moisture content. The days under drought stress were counted after the AWC in the soil reached the desired percentage to allow measurements at precisely determined intervals.

Physiological traits: Relative Chl content, maximum photochemical efficiency ofPSII $\left(\mathrm{F}_{\mathrm{v}} / \mathrm{F}_{\mathrm{m}}\right)$, net photosynthetic rate $\left(P_{\mathrm{N}}\right)$, transpiration rate $(E)$, stomatal conductance $\left(g_{\mathrm{s}}\right)$, relative turgidity (RT), and water-use efficiency (WUE) were measured/calculated at the grain-filling stage on the flag leaf for one selected plant of each genotype per treatment and replication.

The relative Chl content was determined using a chlorophyll meter (SPAD-502, Minolta, Japan). The average of three measurements in the middle of the flag leaf was collected randomly on the $7^{\text {th }}$ day after the drought stress was applied.

Chl fluorescence parameters were measured using a portable fluorometer HandyPEA (Hansatech Instruments Ltd., Norfolk, UK), following the manufacturer's instruction and Kalaji et al. (2014). The dark-adaptation period was about $25 \mathrm{~min}$. Fluorescence parameters $\left(\mathrm{F}_{0}, \mathrm{~F}_{\mathrm{m}}\right)$ 
were recorded and $F_{v} / F_{m}\left(F_{m}-F_{0} / F_{m}\right)$ parameter, which represents the maximum quantum yield of PSII, was automatically calculated.

Plant gas-exchange parameters $\left(P_{\mathrm{N}}, g_{\mathrm{s}}\right.$, and $\left.E\right)$ were measured starting from the $7^{\text {th }}$ day after water stress was applied. The fully expanded flag leaf was selected for one plant per pot per treatment using a $C I R A S$-2 infrared gas analyzer system manufactured by PP Systems Co. (MA, USA). The measurements were set up with the following adjustments: the measured leaf surface area was $4.50 \mathrm{~cm}^{2}$, ambient $\mathrm{CO}_{2}$ concentration $\left(\mathrm{C}_{\mathrm{ref}}\right)$ of $380 \mu \mathrm{mol}\left(\mathrm{CO}_{2}\right) \mathrm{mol}^{-1}$, the temperature of each leaf varied from 24.4 to $25.9^{\circ} \mathrm{C}$, and the leaf chamber gas flow rate (v) was ca. $300 \mathrm{ml} \mathrm{min}^{-1}$. Ambient pressure ranged from 967-973 mbar, and the PAR at the leaf surface reached a maximum of about 1,000 $\mu \mathrm{mol}$ (photon) $\mathrm{m}^{-2} \mathrm{~s}^{-1}$. The value of water-use efficiency was calculated as $P_{\mathrm{N}} / E$.

Plant relative turgidity (RT) was measured using leaf pieces collected from the flag leaf after imposing drought stress. Immediately after cutting the base of lamina, leaves were sealed within plastic bags and transferred quickly to the laboratory. Fresh mass (FM) was determined within two hours after excision. Turgid mass (TM) was obtained after soaking leaves in distilled water in test tubes for $24 \mathrm{~h}$ in the fridge at $4^{\circ} \mathrm{C}$ and in the dark. After that, leaves were quickly and carefully dried by tissue paper in preparation for determining turgid mass. Dry mass (DM) was obtained after oven drying the leaf sample for $48 \mathrm{~h}$ at $80^{\circ} \mathrm{C}$. The RT was calculated according to a flowing formula devised by Barrs and Watherley (1968): RT $=[(\mathrm{FM}-\mathrm{DM}) /$ $(\mathrm{TM}-\mathrm{DM})] \times 100$.

Leaf osmotic potential (OP) was obtained in situ from the leaf material collected at noon. This material was frozen inside an Eppendorf tube with liquid nitrogen. Later on, the material was thawed and placed in a syringe $(1 \mathrm{~mL})$ and the cellular juice was obtained by mechanical pressure. An aliquot of $10 \mu \mathrm{L}$ was used to saturate a disc of filter paper and the osmolality $\left[\mathrm{mmol} \mathrm{kg}^{-1}\right]$ was measured with a Wescor 5520 osmometer (Wescor Inc., Utah, USA). These values were converted to a pressure unit according to the following equation: $\mathrm{OP}[\mathrm{MPa}]=-\mathrm{R} \times \mathrm{T} \times \mathrm{C}$, where $\mathrm{R}$ is the gas constant (0.008314), $\mathrm{T}$ is the temperature measured in the Kelvin scale (298 K in these measurements), and $\mathrm{C}$ is the osmolality $\left[\mathrm{mmol} \mathrm{kg}^{-1}\right]$. The OP was corrected $(\mathrm{OP}+0.1 \mathrm{OP})$ for the dilution of symplastic sap by apoplastic water, assuming $10 \%$ apoplastic water. The OP at full turgor $\left(\mathrm{OP}_{100}\right)$ was calculated, according to Wilson et al. (1979), by the following equation: $\mathrm{OP}_{100}=$ (corrected $\mathrm{OP} \times \mathrm{RT}) / 100$. OA was expressed as the difference between $\mathrm{OP}_{100}$ of leaves of irrigated and stressed plants.

Agro-morphological traits: Plant height (PH), number of tillers (Ti), number of spikes per plant (SN), spike length (SL), 1,000-grain mass (GM), grain yield (GY), biological yield (BY), and harvest index (HI) were recorded during the experiment. At the maturity stage (grain-filling duration), $\mathrm{PH}, \mathrm{SL}, \mathrm{SN}$, and $\mathrm{Ti}$ were recorded on three plants from each replication (total of 12 plants for each tested genotype). The average of three plants for each genotype was used for the analysis. At harvesting time, the average of three plants of each genotype was harvested to measure GM, GY, BY, and HI.

Statistical analysis: The experiment was laid out under RCBD (randomized complete block design) with four replications. Data were subjected to analysis of variance using a GENSTAT v. 18 statistical software. The mean comparisons $\pm \mathrm{SD}$ were carried out to estimate the differences between treatments and genotypes using least significance differences (LSD). A simple correlation analysis was performed to express the relationship among variables of interest.

\section{Results}

Under water stress conditions, the frequency distribution for grain yield among the 40 tested RILs and parental lines Arta and Keel showed a normal distribution (Fig. 1). Cultivar Keel yielded 34\% more than that of cv. Arta (1.85 and $1.38 \mathrm{~g}$ per plant, respectively). Around $38 \%$ of the tested RILs produced a similar grain yield as the parental line Keel; and $56 \%$ of the progeny produced yields with values that were somewhere between those generated by both parental lines.

Morphological parameters: Variations analysis indicated a high significant difference $(P<0.001)$ between genotypes, treatments, and genotype $\times$ treatment interaction for all studied traits (Table 1). This interaction revealed that genotypes performed inconsistently over the treatments. Drought stress treatments during the grain-filling stage significantly decreased values of morphological parameters and grain yield. Except the spike length and 1,000-grain mass, all the morphological parameters were significantly affected by both moderate drought and severe stress (Table 1). As compared to the control treatment, both drought stress levels, MS and SS, affected the plant height, resulting in an average decrease of 10 and $18.5 \%$, respectively.

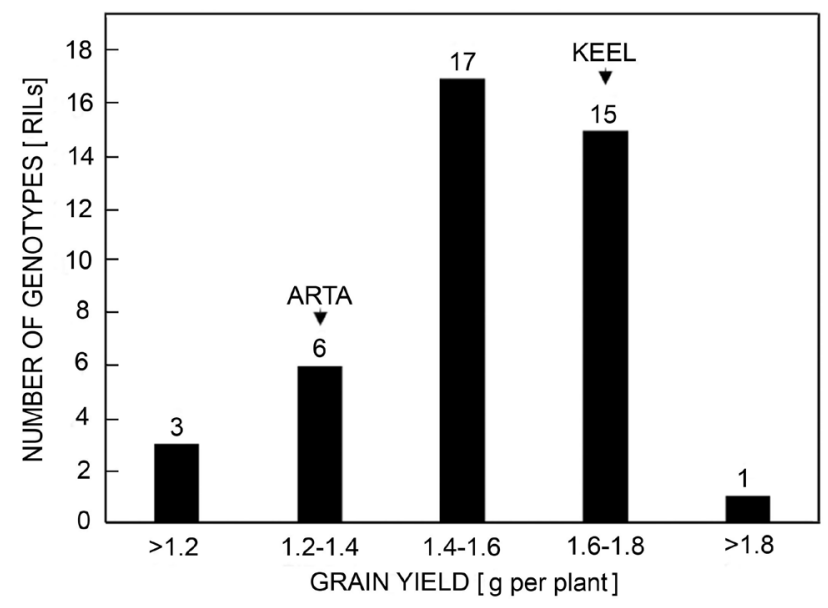

Fig. 1. Frequency distribution of grain yield. The mean performance of the parental lines Arta and Keel is indicated above the bars. 
Table 1. Analysis of variance (mean square) and mean performance with their standard deviation for morphological traits of 40 RILs population $($ Arta $\times$ Keel) under drought stress conditions. PH - plant height $[\mathrm{cm}]$; Ti - number of tillers; SN - number of spikes per plant; $\mathrm{SL}$ - spike length [cm]; GM - 1,000-grain mass [g]; GY - grain yield [g per plant]; BY - biological yield [g per plant]; HI - harvest index [\%]. Treatment means followed by different letters indicate significant difference according to the least significant difference (LSD) test at probability level $0.05 .{ }^{*},{ }^{* *},{ }^{* * *}-$ significance at $0.05,0.01,0.001$ level, respectively. WW - well-watered treatment; MS - mild stress treatment; SS - severe stress treatment.

\begin{tabular}{|c|c|c|c|c|c|c|c|c|}
\hline Traits & Treatments & Mean & $\begin{array}{l}\text { Replications } \\
\text { D.F. }=3\end{array}$ & $\begin{array}{l}\text { Genotypes [RILs] } \\
\text { D.F. }=41\end{array}$ & $\begin{array}{l}\text { Treatments }[\mathrm{T}] \\
\text { D.F. }=2\end{array}$ & $\begin{array}{l}\mathrm{T} \times \mathrm{RILs} \\
\text { D.F. }=82\end{array}$ & $\begin{array}{l}\text { Error } \\
\text { D.F. }=375\end{array}$ & $\mathrm{CV}[\%]$ \\
\hline $\mathrm{PH}$ & $\begin{array}{l}\text { WW } \\
\text { MS } \\
\text { SS }\end{array}$ & $\begin{array}{l}47.05 \pm 4.89^{\mathrm{a}} \\
42.32 \pm 4.33^{\mathrm{b}} \\
38.34 \pm 4.12^{\mathrm{c}}\end{array}$ & 9.93 & $178.56^{* * *}$ & $3,198.94^{* * *}$ & $30.11^{* * *}$ & 5.19 & 5.4 \\
\hline $\mathrm{Ti}$ & $\begin{array}{l}\text { WW } \\
\text { MS } \\
\text { SS }\end{array}$ & $\begin{array}{l}5 \pm 0.66^{\mathrm{a}} \\
4 \pm 0.56^{\mathrm{b}} \\
3 \pm 0.50^{\mathrm{c}}\end{array}$ & 1.17 & $1.44^{* * *}$ & $180.18^{* * *}$ & $0.77^{* * * *}$ & 0.22 & 11.5 \\
\hline $\mathrm{SN}$ & $\begin{array}{l}\text { WW } \\
\text { MS } \\
\text { SS }\end{array}$ & $\begin{array}{l}5 \pm 0.69^{\mathrm{a}} \\
4 \pm 0.55^{\mathrm{b}} \\
3 \pm 0.67^{\mathrm{c}}\end{array}$ & 3.13 & $1.59^{* * *}$ & $243.12^{* * *}$ & $1.21^{* * * *}$ & 0.27 & 14.3 \\
\hline SL & $\begin{array}{l}\text { WW } \\
\text { MS } \\
\text { SS }\end{array}$ & $\begin{array}{l}5.46 \pm 0.73^{\mathrm{a}} \\
5.39 \pm 0.51^{\mathrm{a}} \\
5.24 \pm 0.49^{\mathrm{a}}\end{array}$ & 0.49 & $3.068^{* * *}$ & $2.65^{* * *}$ & $0.55^{* * *}$ & 0.08 & 5.2 \\
\hline GM & $\begin{array}{l}\text { WW } \\
\text { MS } \\
\text { SS }\end{array}$ & $\begin{array}{l}1.54 \pm 0.26^{\mathrm{a}} \\
1.59 \pm 0.16^{\mathrm{a}} \\
1.33 \pm 0.13^{\mathrm{a}}\end{array}$ & 1.02 & $0.23^{* * *}$ & $3.08^{* * * *}$ & $0.108^{* * *}$ & 0.06 & 16.1 \\
\hline GY & $\begin{array}{l}\text { WW } \\
\text { MS } \\
\text { SS }\end{array}$ & $\begin{array}{l}2.21 \pm 0.28^{\mathrm{a}} \\
1.67 \pm 0.34^{\mathrm{b}} \\
0.98 \pm 0.22^{\mathrm{c}}\end{array}$ & 0.80 & $0.42^{* * *}$ & $63.97^{* * *}$ & $0.22^{* * *}$ & 0.03 & 11.7 \\
\hline BY & $\begin{array}{l}\text { WW } \\
\text { MS } \\
\text { SS }\end{array}$ & $\begin{array}{l}5.37 \pm 1.00^{\mathrm{a}} \\
4.16 \pm 0.30^{\mathrm{b}} \\
3.13 \pm 0.30^{\mathrm{c}}\end{array}$ & 3.16 & $2.05^{* * *}$ & $212.08^{* * *}$ & $1.38^{* * *}$ & 0.14 & 8.7 \\
\hline HI & $\begin{array}{l}\text { WW } \\
\text { MS } \\
\text { SS }\end{array}$ & $\begin{array}{l}0.42 \pm 0.06^{\mathrm{a}} \\
0.41 \pm 0.08^{\mathrm{a}} \\
0.31 \pm 0.06^{\mathrm{b}}\end{array}$ & 0.046 & $0.045^{* * *}$ & $0.537^{* * *}$ & $0.0045^{* * *}$ & 0.002 & 11.0 \\
\hline
\end{tabular}

Both MS and SS drought treatments decreased the tiller number (Ti) and the spike number (SN) by 20 and $40 \%$, respectively (Table 1). Spike length (SL) and 1,000-grain mass (GM) were not significantly different between treatments. MS treatment had a higher 1,000-grain mass than that in WW and SS treatments (Table 1). The effect of drought caused 1.3 and $4 \%$ reduction in the spike length under MS and SS treatments, respectively. The RILs with the highest value for the number of tillers, the number of spikes, spike length, and 1,000-grain mass were also characterized by the highest grain yield under three water stress treatments (Tables $1 \mathrm{~S}-3 \mathrm{~S}$, supplement). Among yield component traits, the $\mathrm{SN}$ was significantly and positively correlated with PH $\left(r=0.33^{*}\right)$, Ti $\left(r=0.34^{*}\right)$, $\mathrm{GM}\left(r=0.32^{*}\right)$, and harvest index $\left(r=0.74^{* * *}\right)$ (Table 2$)$.

An important decrease in grain yield was recorded for the different genotypes studied under different water stress levels (Table 1). In comparison to the control treatment, average grain yield for RILs decreased by 24.4 and $55.7 \%$ under MS and SS drought conditions, respectively. No difference was recorded for both parental lines Arta and
Keel in terms of the grain yield decrease (31\%) under moderate drought stress (MS), while a clear difference was observed under severe drought stress (SS) resulting in respective decreases of 61 and $46 \%$ in grain yields for Arta and Keel, respectively (Fig. 2). The highest values for GY and HI were recorded in the tolerant parent Keel under three water treatments, whereas RILs had higher values of GY and HI than the susceptible parent Arta under these treatments (Tables $1 \mathrm{~S}-3 \mathrm{~S}$ ).

A significant difference was observed for biological yield (BY) between water stress conditions, while there were no significant differences in HI between WW and MS treatments (Table 3). After $7 \mathrm{~d}$ of drought, a decrease of 22.5 and $41.7 \%$ was recorded for the BY under MS and SS treatments, respectively; whereas the harvest index was reduced by 2.3 and $26.2 \%$ under both MS and SS, respectively. The highest value for BY was observed for the genotype that showed the highest GY under three water stress treatments (Tables $1 \mathrm{~S}-3 \mathrm{~S}$ ).

Physiological parameters: Results showed highly signifi- 
Table 2. Simple coefficients of correlation among morpho-physiological traits under severe stress condition (10\% AWC) in barley. $\mathrm{Chl}$ - chlorophyll content; $\mathrm{F}_{\mathrm{v}} / \mathrm{F}_{\mathrm{m}}-$ maximum photosynthetic efficiency of PSII; $P_{\mathrm{N}}$ - photosynthetic rate; $E$ - transpiration rate; $g_{\mathrm{s}}$ - stomatal conductance; OP - osmotic potential; RT - relative turgidity; WUE - water-use efficiency; $\mathrm{PH}$ - plant height; Ti - number of tillers; SN - number of spikes per plant; SL - spike length; GM - 1,000-grain mass; GY - grain yield; BY - biological yield; $\mathrm{HI}$ - harvest index. ${ }^{*},{ }^{* *},{ }^{* * *}$ - significance at $0.05,0.01,0.001$ level, respectively.

\begin{tabular}{|c|c|c|c|c|c|c|c|c|c|c|c|c|c|c|c|}
\hline Traits & Chl & $\mathrm{F}_{\mathrm{v}} / \mathrm{F}_{\mathrm{m}}$ & $P_{\mathrm{N}}$ & $E$ & $g_{\mathrm{s}}$ & OP & RT & WUE & $\mathrm{PH}$ & $\mathrm{SL}$ & $\mathrm{SN}$ & $\mathrm{Ti}$ & GM & GY & BY \\
\hline $\mathrm{F}_{\mathrm{v}} / \mathrm{F}_{\mathrm{m}}$ & -0.07 & & & & & & & & & & & & & & \\
\hline$P_{\mathrm{N}}$ & 0.18 & -0.16 & & & & & & & & & & & & & \\
\hline E & 0.14 & -0.20 & 0.17 & & & & & & & & & & & & \\
\hline$g_{\mathrm{s}}$ & 0.20 & -0.10 & 0.20 & $0.82^{* * *}$ & & & & & & & & & & & \\
\hline $\mathrm{OP}$ & -0.26 & 0.02 & -0.04 & $-0.38^{*}$ & $-0.49^{* *}$ & & & & & & & & & & \\
\hline RT & -0.06 & -0.01 & 0.22 & -0.12 & $-0.32^{*}$ & $0.68^{* * *}$ & & & & & & & & & \\
\hline WUE & -0.03 & -0.01 & $0.45^{* *}$ & $-0.68^{* * *}$ & $-0.53^{* * *}$ & 0.20 & 0.15 & & & & & & & & \\
\hline $\mathrm{PH}$ & 0.09 & -0.04 & -0.26 & 0.01 & 0.08 & -0.20 & -0.23 & 0.07 & & & & & & & \\
\hline SL & 0.04 & $-0.34^{*}$ & -0.03 & $0.41^{* *}$ & $0.37^{*}$ & 0.05 & 0.01 & $-0.35^{*}$ & 0.14 & & & & & & \\
\hline SN & $0.32^{*}$ & -0.11 & 0.19 & 0.18 & 0.18 & $-0.46^{* *}$ & -0.24 & 0.09 & $0.33^{*}$ & -0.13 & & & & & \\
\hline $\mathrm{Ti}$ & -0.24 & 0.16 & 0.04 & -0.07 & -0.05 & 0.11 & 0.15 & 0.22 & 0.12 & -0.21 & $0.34^{*}$ & & & & \\
\hline GM & 0.28 & 0.05 & 0.27 & 0.00 & -0.08 & 0.10 & 0.19 & 0.22 & 0.09 & -0.28 & $0.32^{*}$ & 0.07 & & & \\
\hline GY & $0.38^{*}$ & 0.01 & 0.15 & $0.34^{*}$ & 0.30 & $-0.46^{* *}$ & -0.28 & 0.01 & $0.42^{* *}$ & 0.03 & $0.83^{* * *}$ & 0.25 & $0.27^{*}$ & & \\
\hline BY & 0.01 & 0.24 & 0.11 & 0.12 & 0.21 & -0.19 & -0.07 & 0.11 & $0.40^{*}$ & 0.03 & $0.50^{* * *}$ & $0.34^{*}$ & $0.38^{*}$ & $0.56^{* * *}$ & \\
\hline HI & $0.45^{* *}$ & -0.14 & 0.14 & $0.33^{*}$ & 0.25 & $-0.45^{* *}$ & -0.29 & -0.04 & 0.30 & 0.02 & $0.74^{* * * *}$ & 0.13 & 0.13 & $0.90^{* * *}$ & 0.16 \\
\hline
\end{tabular}

cant differences between the 40 studied RILs in response to the different treatments. The significant interaction of treatment $\times$ genotype was observed also for all studied parameters except RT, which indicates a difference between RILs in their response to drought stress (Table 3). No significant differences were observed between WW and MS treatments for the Chl content and between MS and SS for the WUE. An average decrease of 1.0 and $7.3 \%$ of the Chl were recorded for MS and SS treatments, respectively, as compared to the control treatment (Table 3). The maximum efficiency of PSII $\left(\mathrm{F}_{\mathrm{v}} / \mathrm{F}_{\mathrm{m}}\right)$ was significantly affected in three water treatments, although these differences were not very large (Table 3). The reduction of $\mathrm{F}_{\mathrm{v}} / \mathrm{F}_{\mathrm{m}}$ after $7 \mathrm{~d}$ of imposing drought treatments varied from $3.6 \%$ in $\mathrm{SS}$ treatment

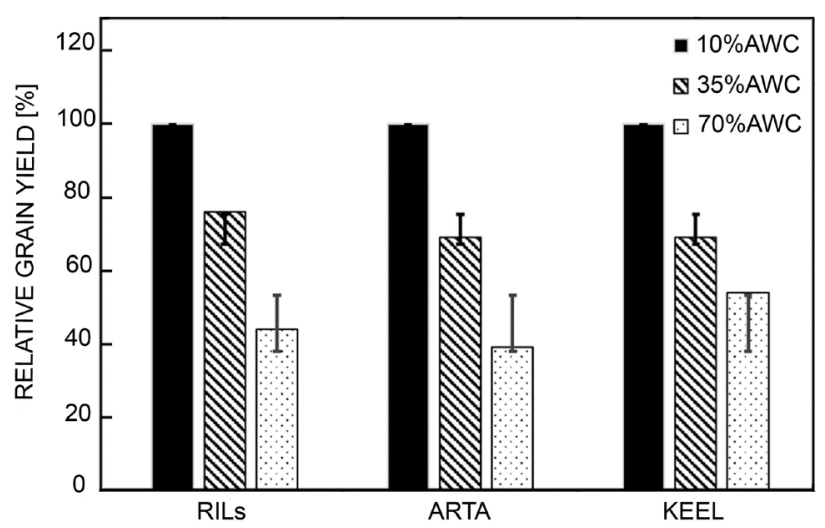

Fig. 2. Relative grain yields of two parents (Arta, Keel) and 40 RILs under three water stress treatments. Values are means $\pm \mathrm{SE}$. $10 \%$ AWC, $35 \%$ AWC, and $70 \%$ AWC - severe stress (SS), mild stress (MS), and well-watered (WW) conditions, respectively.
(10\% AWC) to $2.4 \%$ for MS (35\% AWC) treatment as compared to WW treatment $(70 \%$ AWC). After $7 \mathrm{~d}$ of drought stress, the highest values of Chl content and $\mathrm{F}_{\mathrm{v}} / \mathrm{F}_{\mathrm{m}}$ were observed in RILs which had lower grain yields under SS treatment and higher grain yields under MS and WW treatments (Tables 1S-3S). In our study, there were significant differences in the average of the photosynthetic indicators under three water stress treatments (Table 3 ). At the grain-filling stage, the decrease in $P_{\mathrm{N}}$ was 66.8 and $47.9 \%$ under SS and MS treatments, respectively. The decrease in $g_{\mathrm{s}}$ was 81.9 and $70 \%$ and 74.4 and $58.5 \%$ in $E$, respectively. After $7 \mathrm{~d}$ of drought stress, the highest values for $P_{\mathrm{N}}, g_{\mathrm{s}}$, and $E$ were observed among the RILs showing a high grain yield under three water stress treatments (Tables 1S-3S). Obviously, stressed plants had a lower RT than the nonstressed plants. Water stress significantly influenced the RT, OP, and WUE traits. It reduced the RT by, on average, 31.4 and $11.4 \%$ and OP by, on average, 50.5 and $36.4 \%$ under SS and MS treatments, respectively, compared to WW treatments. The WUE increased by 29 and $23.8 \%$ under SS and MS treatments, respectively, as compared to WW treatments (Table 3). These values can also be used as an indicator of OA capacity, as it represents the variation in OP, with respect to RT over the water stress period. Our results indicated a decline in OP and RT when the severity of water stress increased (Table 4). The values of osmotic adjustment were 0.50 and $0.18 \mathrm{MPa}$ under SS and MS treatments, respectively. After $7 \mathrm{~d}$ of drought stress, the highest value of OP was observed in RIL, which had the lower grain yield under SS treatment and the higher grain yield under MS and WW treatments, while the highest value of RT was observed in RILs that had the lower grain yields and higher grain yields in the WUE under three water treatments (Tables $1 \mathrm{~S}-3 \mathrm{~S}$ ). At 
Table 3. Analysis of variance (mean square) and mean performance with their standard deviation for physiological parameters of 40 RILs population $\left(\right.$ Arta $\times$ Keel) under drought stress conditions. Chl - chlorophyll content [relative unit]; $\mathrm{F}_{\mathrm{v}} / \mathrm{F}_{\mathrm{m}}-$ maximum photosynthetic efficiency of PSII [relative unit]; $P_{\mathrm{N}}-$ photosynthetic rate $\left.\left[\mu \mathrm{mol}\left(\mathrm{CO}_{2}\right) \mathrm{m}^{-2} \mathrm{~s}^{-1}\right)\right] ; E$ - transpiration rate $\left.\left[\mu \mathrm{mol}\left(\mathrm{H}_{2} \mathrm{O}\right) \mathrm{m}^{-2} \mathrm{~s}^{-1}\right)\right] ; g_{\mathrm{s}}-$ stomatal conductance $\left.\left[\mu \mathrm{mol}\left(\mathrm{H}_{2} \mathrm{O}\right) \mathrm{m}^{-2} \mathrm{~s}^{-1}\right)\right]$; OP - osmotic potential [MPa]; RT - relative turgidity [\%]; WUE - water-use efficiency [mol $\left(\mathrm{CO}_{2}\right)$ $\left.\mathrm{mol}^{-1}\left(\mathrm{H}_{2} \mathrm{O}\right)\right]$. Treatment means followed by different letters indicate significant difference according to the least significant difference (LSD) test at probability level $0.05 .^{*},{ }^{* *},{ }^{* * *}-$ significance at $0.05,0.01,0.001$ level, respectively. ns - not significant. WW - wellwatered treatment; MS - mild stress treatment; SS - severe stress treatment.

\begin{tabular}{|c|c|c|c|c|c|c|c|c|}
\hline Traits & Treatments & Mean & $\begin{array}{l}\text { Replications } \\
\text { D.F. }=3\end{array}$ & $\begin{array}{l}\text { Genotypes [RIL] } \\
\text { D.F. }=41\end{array}$ & $\begin{array}{l}\text { Treatments }[\mathrm{T}] \\
\text { D.F. }=2\end{array}$ & $\begin{array}{l}\mathrm{T} \times \text { RILs } \\
\text { D.F. }=82\end{array}$ & $\begin{array}{l}\text { Error } \\
\text { D.F. }=375\end{array}$ & $\mathrm{CV}[\%]$ \\
\hline Chl & $\begin{array}{l}\text { WW } \\
\text { MS } \\
\text { SS }\end{array}$ & $\begin{array}{l}41.90 \pm 3.34^{\mathrm{a}} \\
41.52 \pm 3.88^{\mathrm{a}} \\
38.84 \pm 3.90^{\mathrm{b}}\end{array}$ & 6.09 & $114.59^{* * *}$ & $471.35^{* * *}$ & $25.58^{* * *}$ & 1.86 & 3.3 \\
\hline $\mathrm{F}_{\mathrm{v}} / \mathrm{F}_{\mathrm{m}}$ & $\begin{array}{l}\text { WW } \\
\text { MS } \\
\text { SS }\end{array}$ & $\begin{array}{l}0.83 \pm 0.01^{\mathrm{a}} \\
0.81 \pm 0.02^{\mathrm{b}} \\
0.80 \pm 0.02^{\mathrm{c}}\end{array}$ & 0.00043 & $0.00096^{* * *}$ & $0.0203^{* * *}$ & $0.00077^{* * *}$ & 0.0002 & 1.6 \\
\hline$P_{\mathrm{N}}$ & $\begin{array}{l}\text { WW } \\
\text { MS } \\
\text { SS }\end{array}$ & $\begin{array}{l}5.61 \pm 0.78^{\mathrm{a}} \\
2.92 \pm 0.65^{\mathrm{b}} \\
1.86 \pm 0.44^{\mathrm{c}}\end{array}$ & 1.86 & $1.72^{* * *}$ & $630.64^{* * *}$ & $1.59^{* * *}$ & 0.17 & 12.1 \\
\hline E & $\begin{array}{l}\text { WW } \\
\text { MS } \\
\text { SS }\end{array}$ & $\begin{array}{l}0.94 \pm 0.29^{\mathrm{a}} \\
0.39 \pm 0.13^{\mathrm{b}} \\
0.24 \pm 0.07^{\mathrm{c}}\end{array}$ & 0.16 & $0.17^{* * *}$ & $26.65^{* * *}$ & $0.12^{* * *}$ & 0.006 & 14.4 \\
\hline$g_{\mathrm{s}}$ & $\begin{array}{l}\text { WW } \\
\text { MS } \\
\text { SS }\end{array}$ & $\begin{array}{l}82.74 \pm 24.93^{\mathrm{a}} \\
24.81 \pm 8.58^{\mathrm{b}} \\
14.97 \pm 4.91^{\mathrm{c}}\end{array}$ & 0.80 & $1,200.05^{* * *}$ & $210,475.62^{* * *}$ & $838.48^{* * *}$ & 1.19 & 2.7 \\
\hline OP & $\begin{array}{l}\text { WW } \\
\text { MS } \\
\text { SS }\end{array}$ & $\begin{array}{l}-1.78 \pm 0.32^{\mathrm{a}} \\
-2.29 \pm 0.12^{\mathrm{b}} \\
-3.60 \pm 0.52^{\mathrm{c}}\end{array}$ & 0.03 & $0.55412^{* * *}$ & $148.13^{* * *}$ & $0.4750^{* * *}$ & 0.021 & 5.7 \\
\hline RT & $\begin{array}{l}\text { WW } \\
\text { MS } \\
\text { SS }\end{array}$ & $\begin{array}{l}0.70 \pm 0.04^{\mathrm{a}} \\
0.62 \pm 0.03^{\mathrm{b}} \\
0.48 \pm 0.05^{\mathrm{c}}\end{array}$ & 0.14 & $0.012^{*}$ & $1.98^{* * *}$ & $0.0046^{\mathrm{ns}}$ & 0.008 & 14.9 \\
\hline WUE & $\begin{array}{l}\text { WW } \\
\text { MS } \\
\text { SS }\end{array}$ & $\begin{array}{l}6.1 \pm 1.58^{\mathrm{a}} \\
8.0 \pm 2.41^{\mathrm{b}} \\
8.6 \pm 3.20^{\mathrm{b}}\end{array}$ & 26.57 & $27.64^{* * *}$ & $2.66^{* * *}$ & $22.28^{* * *}$ & 2.36 & 20.1 \\
\hline
\end{tabular}

Table 4. Calculation of osmotic adjustment (OA) under drought stress conditions in barley. WW - well-watered treatment; MS - mild stress treatment; SS - severe stress treatment.

\begin{tabular}{lllll}
\hline Treatments & Relative turgidity [\%] & Osmotic potential [MPa] & Osmotic potential at full turgor [MPa] & Osmotic adjustment [MPa] \\
\hline WW & 70 & -1.68 & -1.18 & - \\
MS & 62 & -2.19 & -1.36 & 0.18 \\
SS & 48 & -3.50 & -1.68 & 0.50 \\
\hline
\end{tabular}

grain filling, the WUE of plants increased significantly with water supply, irrespective of genotype (Table 3 ).

Correlation analysis: The application of correlation analysis among yield component traits showed that the $\mathrm{SN}$ was significantly and positively correlated with PH $\left(r=0.33^{*}\right)$, $\mathrm{Ti}\left(r=0.34^{*}\right), \mathrm{GM}\left(r=0.32^{*}\right)$, and HI $\left(r=0.74^{* * *}\right)$ (Table 2$)$. A positive and significant correlation was recorded between GY and PH $\left(r=42^{* *}\right)$, SN $\left(r=0.83^{* * *}\right)$, BY $\left(r=0.56^{* * *}\right)$, GM $\left(r=0.27^{*}\right)$, and HI $\left(r=0.90^{* * *}\right)$ (Table 2). BY was significantly and positively correlated with PH $\left(r=0.40^{*}\right), \mathrm{Ti}\left(r=0.34^{*}\right), \mathrm{SN}\left(r=0.50^{* * *}\right)$, and GM $\left(r=0.38^{*}\right)$ (Table 2). The Chl content exhibited positive and significant association with SN $\left(r=0.32^{*}\right)$, GY $(r=$ $\left.0.38^{*}\right)$, and $\mathrm{HI}\left(r=0.45^{* *}\right)$, while $\mathrm{F}_{\mathrm{v}} / \mathrm{F}_{\mathrm{m}}$ showed a negative significant association with SL $\left(r=-0.34^{*}\right)$ (Table 2).

A positive and significant correlation was recorded between $E$ and $g_{\mathrm{s}}\left(r=0.82^{* * *}\right)$, GY $\left(r=0.34^{*}\right)$, HI $(r=$ $\left.0.33^{*}\right)$, and SL $\left(r=0.40^{* *}\right)$ (Table 2$)$. A negative and significant correlation was found between $g_{\mathrm{s}}$ and OP $\left(r=-0.49^{* *}\right)$, RT $\left(r=-0.32^{*}\right)$, and WUE $\left(r=-0.53^{* * *}\right)$, while this trait correlated positively and significantly 
$\left(r=0.37^{*}\right)$ with SL (Table 2).

OP was associated negatively and significantly with $E\left(r=-0.38^{*}\right), \mathrm{GY}\left(r=-0.46^{* *}\right)$, SN $\left(r=-0.46^{* *}\right)$, and HI $\left(r=-0.45^{* *}\right)$, while it showed positive and significant correlations with RT $\left(r=0.68^{* * *}\right)$ (Table 2$)$. A negative and significant correlation was recorded between WUE and $E\left(r=-0.68^{* * *}\right)$ and SL $\left(r=-0.35^{*}\right)$, whereas a positive and significant correlation was found with $P_{\mathrm{N}}\left(r=0.45^{* *}\right)$ (Table 2).

\section{Discussion}

The effect of water stress during the grain-filling stage decreased the grain yield and yield components, and these results are consistent with previous studies (Samarah 2005, Bogale et al. 2011, Ahmadizadeh 2013, Rollins et al. 2013b, Saeidi and Abdoli 2015). Drought caused strong reductions in plant height, compared to control in Arta, but not in tolerant parent (Keel) (Tables 1S-3S). Ahmadizadeh (2011) reported that tall genotypes have this ability to extract more water from the soil. Many plants including cereals store carbohydrates in the vegetative organs such as stems and leaves before reproductive stage and then remobilize them into the grains during grain-filling stage under drought conditions. The coincidence of main effect QTL for plant height and yield indicated that average yield was mainly determined by plant height (von Korff et al. 2008), and the number of tillers and spikes decreased under MS and SS treatments. Similar to these findings, Samarah (2005) reported that drought stress reduced plants tillers by 25 and $4.2 \%$, fertile spikes by 50 and $50 \%$, and grain yield by 57 and $51 \%$ under severe and mild stress conditions, respectively, compared to plants under well-watered conditions. A significant and positive correlation was found between SN and Ti, GM, GY, BY, and HI (Table 2). Traits, which have a positive and significant correlation with grain yield, can be considered as enhancing performance under water stress. Rollins et al. (2013a), who also studied the same population, reported a significant and positive correlation between 1,000-grain mass and grain yield per plant $\left(r=0.42^{* * *}\right)$, which was higher than we identified in our study $\left(0.27^{*}\right)$, but they found a lower correlation between 1,000-grain mass and biological yield $\left(0.16^{*}\right)$ compared to our study $\left(0.38^{*}\right)$. Grain yield (GY) per plant is the ultimate result of all physiological and agronomical responses of cultivars to drought stress conditions (Jatoi et al. 2011). Drought treatments caused significant reductions in GY and BY, compared to control (Table 1). Similar results were found in previous studies under both field and greenhouse experiments (Ceccarelli 1994, Li et al. 2006, Guo et al. 2009, Rollins et al. 2013a,b). Some RILs $(9.2 \%)$ had a higher relative GY than the two parents Arta and Keel under MS treatment (Fig. 2). According to our results, mild stress treatments are more suitable water level in this study. Significant differences were found in HI under water stress conditions, while no significant differences in HI were found between WW and MS treatments (Table 1). This indicates that HI expresses the ability of plants to allocate photosynthetic assimilates to produce grain (Saeidi et al. 2015). Ahmadizadeh et al.
(2011) found that wheat cultivars with the high biological yield and harvest index have high grain yields under stress conditions.

During the grain-filling stage, water deficits significantly decreased the Chl content by $7.3 \%$ (Table 3 ). This is in agreement with the results earlier obtained in barley 20\% (Li et al. 2006), 22.2\% (Guo et al. 2009), and 7.8\% in bread wheat (Moradi et al. 2015). Positive and significant correlations $\left(r=0.32^{*}, r=0.38^{*}\right.$, and $\left.r=0.45^{* *}\right)$ were found between $\mathrm{Chl}$ and $\mathrm{SN}, \mathrm{GY}$, and HI respectively. It was reported by Li et al. (2006) that Chl content positively correlated $\left(r=0.67^{*}\right)$ with GY under drought stress conditions, which is $43 \%$ higher than that we observed in our study. The use of $\mathrm{Chl}$ fluorescence measurements as a nondestructive method proved to be reliable for monitoring photosynthesis events and judging the physiological status of the plant (Li et al. 2006, Kalaji and Guo 2008). The ratio of $F_{v} / F_{m}$ indicates the potential photochemical yield of PSII and quantum efficiency, and it is an important index for evaluating photosynthesis efficiency (Baum et al. 2007). At the grain-filling stage, maximum efficiency of PSII $\left(\mathrm{F}_{\mathrm{v}} / \mathrm{F}_{\mathrm{m}}\right)$ was significantly affected under three water treatments (Table 3). Many studies indicated that the latter parameter decreases under limited soil moisture (Baum et al. 2007, Guo et al. 2009, Moradi et al. 2015). The fluorescence ratios and yield values were altered most significantly after $7 \mathrm{~d}$ of stress imposition. Therefore, Kalaji et al. (2011a) did not recommend this parameter for early detection under such stress.

Photosynthesis is an important factor controlling growth and yield production in plants. Reduction on photosynthesis after flowering due to drought stress affected the dry matter production and therefore the grain yield was reduced (Table 3). Bogale et al. (2011) showed that water deficit treatments at grain-filling stage significantly affected gasexchange parameters. Photosynthesis, transpiration, and stomatal conductance were reduced under water regime conditions (Table 3). These findings come in agreement with previous barley and wheat research (Samarah 2005, Roohi et al. 2013, Kalaji et al. 2014, 2017; Saeidi and Abdoli 2015). A positive and high significant correlation was recorded between $E$ and $g_{\mathrm{s}}\left(r=0.82^{* * *}\right.$; Table 2). Touchan et al. (2010) reported that decreasing leaf water content initially induces stomatal closure, imposing a decrease in the supply of $\mathrm{CO}_{2}$ to mesophyll cells and consequently decreasing the rate of leaf photosynthesis. A high reduction in $g_{\mathrm{s}}$ of 81.9 and $70 \%$ under SS and MS conditions, respectively, is considered the best indicator for drought stress, compared to other traits used in this study (Table 3). Monitoring gas exchange in plants is a common approach, with $g_{\mathrm{s}}$ reported as one of the most sensitive indicators under drought stress (Medrano et al. 2002). This suggests an increased susceptibility of stomatal conductivity to water stress, resulting in an increase in the apparent mesophyll resistance, which can be differentiated among different genotypes of cereals (Roohi et al. 2013). A negative correlation was found between $g_{\mathrm{s}}$ and RT $\left(r=-0.32^{*}\right.$; Table 2$)$. The genotypes manifested minimum $g_{s}$, and although these cultivars exhibited higher RT, the $E$ was much lower under stress conditions, enhancing 
survival in drought environments (Jatoi et al. 2011). According to Saeidi and Abdoli (2015), a greater decline in $g_{s}$ was observed in tolerant cultivars compared to susceptible ones, and it can therefore be concluded that under water stress, the $P_{\mathrm{N}}$ of tolerant cultivars is primarily limited by stomatal rather than nonstomatal factors.

The water content at full turgor should be used as the basis for relative turgidity - not dry mass, nor fresh mass, or area (Barrs and Watherley 1968). RT is useful for determining physiological water status in plants, and it is high at the initial stages of leaf development (Ahmadizadeh 2013). In our study, the RT and OP were reduced under water stress treatment (Table 3). A positive and highly significant correlation was recorded between RT and OP $\left(r=0.68^{* * *}\right)$, while a negative and insignificant correlation was observed between RT and $E(r=-0.12$; Table 2) indicating that the RT was most likely reduced by an increase in $E$ (Rollins et al. 2013b). Bogale et al. (2011) reported that water deficit caused a reduction of the RT of leaves, but genotypes demonstrated variation in the maintenance of RT under both water deficit and wellwatered conditions. The values of OA were 0.50 and 0.18 MPa under SS and MS treatments, respectively (Table 4). A negative and significant correlation was found between OP and $g_{\mathrm{s}}$, OP and $E\left(r=-0.49^{* *}, r=-0.38^{*}\right)$, respectively. This could be explained by a lowering of the cell OP, which in turn attracts water into the cell and thereby maintains its turgor (González et al. 2008). Accumulation of solutes in roots leads to a lowering of the OP of the root, which maintains the driving force for extracting soil water under water deficit conditions (Moinuddin et al. 2005). Thus, OA helps plants perform better in drought in terms of growth and productivity by maintaining turgor and water supply to the plant, which thereby maintains a comparatively higher photosynthetic rate and growth (Ludlow and Muchow 1990). WUE significantly increased as compared to control conditions at the grain-filling stage. A negative and significant correlation was recorded between WUE and $E$, WUE and $g_{\mathrm{s}}\left(r=-0.68^{* * *} ; r=-0.53^{*}\right)$, respectively (Table 2). An increase in WUE could be due to higher reduction of $E$ than $P_{\mathrm{N}}$ under water deficit conditions (Bogale et al. 2011).

According to the three parameters (OA, RT, and WUE), 12 tolerant genotypes (RILs) performed well under severe stress treatment (Table 1S). A higher WUE may be related to either higher growth and photosynthesis or to lower growth rates due to stomatal closure (Pita et al. 2005).

Conclusion: Drought stress during the grain-filling period reduced morpho-physiological traits and grain yield. Chlorophyll content affected the grain yield and was associated positively with yield increases under three water treatments. The results of stomatal conductance showed a higher reduction under drought stress conditions compared to other physiological parameters. Stomatal conductance is one of the most sensitive indicators under drought stress. The great decline in stomatal conductance was observed in tolerant genotypes compared to susceptible ones. Stomatal limitation of the net photosynthetic rate under stress conditions may vary in susceptible and tolerant genotypes. Well-watered plants produced more tillers and consequently more fertile spikes and grains compared with mild and severe stress treatments. The highest values of tillers, spikes, 1,000-grain mass, and biological yields were found in genotypes with the higher grain yields under three water stress treatments. Therefore, these traits could be considered as useful tools during crop breeding procedures. Under mild stress treatment (35\% AWC), the genotypes (RILs) had higher grain yields than the two parents (Arta and Keel) and there were no significant differences in the means of RILs for WUE traits between severe and mild stress conditions. Therefore, our study suggests the mild stress treatment should be considered as a suitable water level. Correlation analysis showed that the correlation between morphological and yield traits was positive and significant, while the correlation was negative and significant between water-related parameters and stomatal conductance, transpiration and also between osmotic potential and number of seed, grain yield, harvest index. Therefore, the relationships could serve as the selection criteria to screen genotypes for drought tolerance and potentially higher yields under water stress treatments.

\section{References}

Ahmadizadeh M.: Physiological and agro-morphological response to drought stress. - Middle East J. Sci. Res. 13: 9981009, 2013.

Ahmadizadeh M., Shahbazi H., Valizadeh M., Zaefizadeh M.: Genetic diversity of durum wheat landraces using multivariate analysis under normal irrigation and drought stress conditions. - Afr. J. Agr. Res. 6: 2294-2302, 2011.

Barrs H.D., Watherley P.E.: A re-examination of the relative turgidity technique for estimating water deficit in leaves. Aust. J. Biol. Sci. 15: 413-428, 1968.

Baum M., von Korff M., Guo P. et al.: Molecular approaches and breeding strategies for drought tolerance in barley. In: Varshney R.K., Tuberosa R. (ed.): Genomic-Assisted Crop Improvement. Vol. 2. Genomics Applications in Crops. Pp. 51-79. Springer, Dordrecht 2007.

Behbahanizadeh S.A., Akbari G.A., Shahbazi M., Alahdadi I.: Relations between barley root traits and osmotic adjustment under terminal drought stress. - J. Agr. Sci. 6: 112-119, 2014.

BogaleA., Tesfaye K., Geleto T.: Morphological and physiological attributes associated to drought tolerance of Ethiopian durum wheat genotypes under water deficit condition. - J. Biodivers. Environ. Sci. 1: 22-36, 2011.

Ceccarelli S.: Specific adaptation and breeding for marginal conditions. - Euphytica 77: 205-219, 1994.

Chéour F., Kaddachi I., Achouri D. et al.: Effects of water stress on relative water, chlorophylls and proline contents in barley (Hordeum vulgare L.) leaves. - J. Agr. Vet. Sci. 7: 13-16, 2014.

Dunic J.A., Lepedus H., Simic D. et al.: Physiological response to different irradiation regimes during barley seedlings growth followed by drought stress under non-photoinhibitory light. J. Agr. Sci. 7: 69-83, 2015.

González A., Martín I., Ayerbe L.: Yield and osmotic adjustment capacity of barley under terminal water-stress conditions. J. Agron. Crop Sci. 194: 81-91, 2008.

Grando S., Baum M., Ceccarelli S. et al.: QTLs for straw quality characteristics identified in recombinant inbred lines of a Hordeum vulgare $\times H$. spontaneum cross in a Mediterranean environment. - Theor. Appl. Genet. 110: 688-695, 2005. 
Grando S., von Bothmer R., Ceccarelli S.: Genetic diversity of barley: use of locally adapted germplasm to enhance yield and yield stability of barley in dry areas. - In: Cooper H.D., Spillane C., Hodgink T. (ed.): Broadening the Genetic Base of Crop Production. Pp. 351-372. CABI Publishing, Wallingford 2001.

Guo P., Baum M., Grando S. et al.: Differentially expressed genes between drought-tolerant and drought-sensitive barley genotypes in response to drought stress during the reproductive stage. - J. Exp. Bot. 60: 3531-3544, 2009.

Jatoi W.A., Baloch M.J., Kumbhar M.B. et al.: Effect of water stress on physiological and yield parameters at anthesis stage in elite spring wheat cultivars. - Sarhad J. Agric. 27: 59-65, 2011.

Kalaji H.M., Bosa K., Kościelniak J., Hossain Z.: Chlorophyll $a$ fluorescence - A useful tool for the early detection of temperature stress in spring barley (Hordeum vulgare L.). Omics 15: 925-934, 2011a.

Kalaji H.M., Carpentier R., Allakhverdiev S.I., Bosa K.: Fluorescence parameters as an early indicator of light stress in barley. - J. Photoch. Photobio. B 112: 1-6, 2012.

Kalaji H.M., Govindjee, Bosa K. et al.: Effects of salt stress on photosystem II efficiency and $\mathrm{CO}_{2}$ assimilation of two Syrian barley landraces. - Environ. Exp. Bot. 73: 64-72, 2011 b.

Kalaji H.M., Guo P.: Chlorophyll fluorescence: A useful tool in barley plant breeding programs. - In: Sanchez A., Gutierrez S.J. (ed.): Photochemistry Research Progress. Pp. 439-463. Nova Science Publishers, New York 2008.

Kalaji H.M., Schansker G., Brestic M. et al.: Frequently asked questions about chlorophyll fluorescence, the sequel. Photosynth. Res. 132: 13-66, 2017.

Kalaji H.M., Schansker G., Ladle R.J. et al.: Frequently asked questions about in vivo chlorophyll fluorescence: practical issues. - Photosynth. Res. 122: 121-158, 2014.

Li R., Guo P., Baum M. et al.: Evaluation of chlorophyll content and fluorescence parameters as indicators of drought tolerance in barley. - Agr. Sci. China 5: 751-757, 2006.

Lonbani M., Arzani A.: Morpho-physiological traits associated with terminal drought stress tolerance in triticale and wheat. Agron. Res. 9: 315-329, 2011.

Ludlow M.M., Muchow R.C.: A critical evaluation of traits for improving crop yields in water-limited environments. - Adv. Agron. 43: 107-153, 1990.

Medrano H., Escalona J.M., Bota J. et al.: Regulation of photosynthesis of $\mathrm{C}_{3}$ plants in response to progressive drought: Stomatal conductance as a reference parameter. Ann. Bot.-London 89: 895-905, 2002.

Moinuddin, Fischer R.A., Sayre K.D., Reynolds M.P.: Osmotic adjustment in wheat in relation to grain yield under water deficit environments. - Agron. J. 97: 1062-1071, 2005.
Moradi Z., Farshadfar E., Shirvani H.: Screening of drought tolerant genotypes in bread wheat (Triticum aestivum) using morpho-physiological traits and integrated selection index. Biol. Forum 7: 163-172, 2015.

Pinheiro C., Chaves M.M.: Photosynthesis and drought: Can we make metabolic connections from available data? - J. Exp. Bot. 62: 869-882, 2011.

Pita P., Cañas I., Soria F. et al.: Use of physiological traits in tree breeding for improved yield in drought-prone environments. The case of Eucalyptus globulus. - Invest. Agrar. Sist. Recur. For. 14: 383-393, 2005.

Rollins J.A., Drosse B., Mulki M.A. et al.: Variation at the vernalisation genes $\mathrm{Vrn}-\mathrm{H} 1$ and $\mathrm{Vrn}-\mathrm{H} 2$ determines growth and yield stability in barley (Hordeum vulgare) grown under dryland conditions in Syria. - Theor. Appl. Genet. 126: 28032824, 2013a.

Rollins J.A., Habte E., Templer S.E. et al.: Leaf proteome alterations in the context of physiological and morphological responses to drought and heat stress in barley (Hordeum vulgare L.). - J. Exp. Bot. 64: 3201-3212, 2013b.

Roohi E., Tahmasebi-Sarvestani Z., Modarres-Sanavy S.A.M., Siosemardeh A.: A comparative study on the effect of soil water stress on photosynthesis function of triticale, bread wheat and barley. - J. Agr. Sci. Tech. 15: 215-228, 2013.

Ryan J., Estefan G., Rashid A.: Soil and Plant Analysis Laboratory Manual. $2^{\text {nd }}$ Edition. Pp. 172. ICARDA, Aleppo 2001.

Saeidi M., Abdoli M.: Effect of drought stress during grain filling on yield and its components, gas exchange variables, and some physiological traits of wheat cultivars. - J. Agr. Sci. Tech. 17: 885-898, 2015.

Saeidi M., Ardalan S., Jalali-Honarmand S.: Evaluation of drought stress at vegetative growth stage on the grain yield formation and some physiological traits as well as fluorescence parameters of different bread wheat cultivars. Acta Biol. Szeged. 59: 35-44, 2015.

Samarah N.H.: Effects of drought stress on growth and yield of barley. - Agron. Sustain. Dev. 25: 145-149, 2005.

Touchan H., Hussein M.H., Aldarir A.N. et al.: Evaluation of photosynthetic parameters in recombinant inbred lines of barley (Hordeum vulgare L.) in relation to grain yield under water-stress conditions. - Arab. J. Arid Environ. 3: 34-46, 2010.

von Korff M., Grando S., Del Greco A. et al.: Quantitative trait loci (QTL) associated with agronomic performance of barley under drought. - Theor. Appl. Genet. 117: 653-669, 2008.

Wilson J.R., Fischer M.J., Schulze E.-D. et al.: Comparison between pressure volume and dew point hygrometry techniques for determining the water relations characteristics of grass and legume leaves. - Oecologia 41: 77-88, 1979.

(C) The authors. This is an open access article distributed under the terms of the Creative Commons BY-NC-ND Licence. 